\title{
Ocular Morbidity among Paediatric Age Group Population Attending at a Tertiary Care Hospital: A Cross Sectional Study
}

\author{
Mehul Sanghavi \\ Associate Professor, Department of Ophthalmology, Vedantaa Institute of Medical Sciences, Dahanu Road, \\ Palghar.
}

\begin{abstract}
Background: Ocular morbidities in children can have a serious impact on development; education and quality of life in children hence require prompt attention. This study was conducted with an objective to determine the pattern of ocular morbidity.

Materials \& Methods: This cross sectional study was conducted at the Vedantaa Institute of Medical Sciences, Palghar between February 2021 to April 2021 were involving 55 children. Data were tabulated in Microsoft Excel and analysed by SPSS version 23.0. All children who attended the Outpatient department of Ophthalmology during the study period were included and children whose parents did not give consents for examinations were excluded.

Results: The most common ocular morbidity encountered was refractive errors (30.9\%) followed by Conjunctivitis (20.0\%) and ocular trauma $(9.1 \%)$ in the age group of $10-15$ years. Conclusion: Majority of ocular morbidities are preventable or treatable with proper use of eye care facilities is the need of the hour.
\end{abstract}

Keywords: Ocular Trauma, Morbidity, Refractive Error, Conjunctivitis.

\section{INTRODUCTION}

The children mostly affected by the ocular disorder. Childhood ocular morbidity can have a serious impact on development, education and quality of life in children. Blindness in children accounts for $1 / 3$ rd of the economic cost of blindness although it represents $<4 \%$ of the overall magnitude. Childhood blindness is the second largest cause of blind person years, following cataract. Globally approximately 70 million blind person years are caused by childhood blindness. ${ }^{(1)}$ Literature analysis indicates that childhood blindness varies from 1.2 per 1000 children in very low income countries to 0.3 per 1000 children in high income countries. ${ }^{(2)}$ India has an estimated 320000 blind children, more than any other country in the world. Estimated national prevalence of childhood blindness / low vision is 0.80 per 1000 in India. ${ }^{(3)}$

Notably, information pertaining to the prevalence of ocular morbidities in younger populations, especially in children is rare. Recent studies have highlighted the fact that more than $30 \%$ of India blind population lose their vision during childhood. Intriguingly, many of them belong to less than 5 years age ${ }^{(4)}$. Very few hospital based studies are available on childhood ocular morbidity in the western region of Maharashtra. With this background, the present study was designed to estimate the prevalence of various ophthalmic morbidities in children presenting in the Outpatient Department of Ophthalmology, Vedantaa Institute of Medical Sciences, Palghar.

\section{MATERIALS \& METHODS}

This is a hospital based cross sectional study was conducted in the Outpatient Department of Ophthalmology, Vedantaa Institute of Medical Sciences, Palghar from February 2021 to April 2021. All the patients aged up to 15 years 
Mehul Sanghavi. Ocular morbidity among paediatric age group population attending at a tertiary care hospital: a cross sectional study.

attending Ophthalmology Outpatient Department on working days during the study period were included in the study by convenient sampling method. Those who were uncooperative and came for follow up visit were excluded from the study. Total 55 children formed the study population.

All patients visual acuity was examined using Snellen's chart in both English and Marathi. Automated refraction and subjective refraction was done in older children with refractive error (Visual acuity less than 6/6). Cycloplegia refraction was not done at the school level. Color vision was tested using the Ishihara Plates in children with visual acuity better than 20/200 in broad-daylight. Further evaluation was performed by an ophthalmologist. Extra-ocular movements, Hirschberg corneal reflex test, and cover-uncover tests were done for squint assessment. Slit-lamp bio-microscopy was used to evaluate the anterior segment including lids, lacrimal sac, conjunctiva, cornea, anterior chamber, pupil, iris, and lens. Whenever required, a dilated fundus examination with indirect ophthalmoscopy was done following the instillation of tropic amide $(0.8 \%)+$ phenylephrine $(5 \%)$ eye drops by the ophthalmologist.

\section{Statistical analysis}

The data was arranged in an MS Excel sheet and statistical analysis was done. The number and percentage of patients according to age groups, gender and Ocular morbidity were calculated. The data was analysed using SPSS version 23.9 for Mac OS (IBM SPSS). A p Value of less than 0.05 was considered to be statistically significant.

\section{RESULTS}

Total 55 paediatric patients attended Outpatient department of Ophthalmology out of which $30(54.5 \%)$ were males \& 25 $(45.5 \%)$ were females. $30(54.5 \%)$ were belonged to the age group between $10-15$ years followed by the $18(32.7 \%)$ were belonged to the age group between $5-10$ years and $7(12.7 \%)$ were belonged to the age group between 0 - 5 years.

Table No. 1: Age and Gender wise distribution of the study subjects $(n=55)$.

\begin{tabular}{|l|l|l|l|}
\hline \multirow{2}{*}{ Age group (Years) } & Gender & \multirow{2}{*}{ Total } \\
\cline { 2 - 3 } & Male & Female & \\
\hline $0-5$ Years & $5(9.1 \%)$ & $2(3.6 \%)$ & $7(12.7 \%)$ \\
\hline $5-10$ Years & $10(18.2 \%)$ & $8(14.5 \%)$ & $18(32.7 \%)$ \\
\hline $10-15$ Years & $15(27.3 \%)$ & $15(27.3)$ & $30(54.5 \%)$ \\
\hline Total & $30(54.5 \%)$ & $25(45.5 \%)$ & $55(100.0 \%)$ \\
\hline
\end{tabular}

In the below table observed that amongst all the ocular complaints, diminution of vision (DOV) were 19 $(34.5 \%)$ cases, followed by the headache were $5(9.1 \%)$ cases, and itching in eyes were $5(9.1 \%)$ cases frequently reported \& very few study subjects reported symptoms such as watering of eyes were $3(5.5 \%)$, discharge were $3(5.5 \%)$, asthenia were 3 $(5.5 \%)$, foreign body sensation were 2 $(3.6 \%)$ and loss of vision were $1(1.8 \%)$ cases.

Table No. 2: Frequency Distribution of cases according to the main presenting complaints in the study subjects.

\begin{tabular}{|l|l|l|}
\hline Complaints & No. Of Patients & Percent \\
\hline Asthenia & 3 & $5.5 \%$ \\
\hline Discharge & 3 & $5.5 \%$ \\
\hline Diminution of Vision (DOV) & 19 & $34.5 \%$ \\
\hline Foreign body sensation & 2 & $3.6 \%$ \\
\hline Headache & 5 & $9.1 \%$ \\
\hline Itching & 5 & $9.1 \%$ \\
\hline Loss of Vision & 1 & $1.8 \%$ \\
\hline Pain of Eyes & 3 & $5.5 \%$ \\
\hline Photophobia & 3 & $5.5 \%$ \\
\hline Redness & 4 & $7.3 \%$ \\
\hline Swelling & 3 & $5.5 \%$ \\
\hline Traumatic Injury & 1 & $1.8 \%$ \\
\hline Watering & 3 & $5.5 \%$ \\
\hline Total & 55 & $100.0 \%$ \\
\hline
\end{tabular}

In the below table shows that the Refractive errors was (17 cases) the most common ocular disorder observed. This was followed by allergic conjunctivitis (11 cases) and infectious eyes disease (6 cases). However phthisis bulbs (1 cases) followed by retinal disorders (1 cases) were the least common causes. Amongst the Refractive errors, majority $7(41.2 \%)$ of the patients were myopia followed by the $6(35.3 \%)$ of the patients were astigmatism and $4(23.5 \%)$ were Hypermetropia.

In the above table shows that the age wise distribution of ocular morbidity, amongst Refractive errors was $21.8 \%$ of the 
Mehul Sanghavi. Ocular morbidity among paediatric age group population attending at a tertiary care hospital: a cross sectional study.

patients belonging to the $10-15$ years followed by the Allergic Conjunctivitis was $10.9 \%$ of the patients belonging to the age group between 10 - 15 years and Others morbidity was $9.1 \%$ of the patients belonging to the age group between $10-15$ years.

Table No. 3: Patients distribution according to the ocular morbidity.
\begin{tabular}{|l|l|l|l|}
\hline Ocular Morbidity & No. Of Patients & Percent \\
\hline Allergic Conjunctivitis & 11 & $20.0 \%$ \\
\hline Congenital Eye Disease & 5 & $9.1 \%$ \\
\hline Infectious of the eye and adnexa & 6 & $10.9 \%$ \\
\hline Ocular Trauma & 5 & $9.1 \%$ \\
\hline Phthisis bulbs & 1 & $1.8 \%$ \\
\hline Refractive error & Myopia & 7 & $12.7 \%$ \\
\cline { 2 - 4 } & Astigmatism & 6 & $10.9 \%$ \\
\cline { 2 - 4 } & Hypermetropia & 4 & $7.3 \%$ \\
\hline Disorders of the retina & & 1 & $1.8 \%$ \\
\hline Vitamin A deficiency & & 2 & $3.6 \%$ \\
\hline Others & 7 & $12.7 \%$ \\
\hline Total & 55 & $100.0 \%$ \\
\hline
\end{tabular}

Table No. 4: Age wise distribution of patients with Ocular Morbidity

\begin{tabular}{|l|l|l|l|l|}
\hline \multirow{2}{*}{ Ocular Morbidity } & \multicolumn{3}{|l|}{ Age Group } & \multirow{2}{*}{ Total } \\
\cline { 2 - 4 } & 0 - 5 Years & $\mathbf{5 ~ - 1 0 ~ Y e a r s ~}$ & $\mathbf{1 0}$ - 15 Years & \\
\hline Allergic Conjunctivitis & $1(1.8 \%)$ & $4(7.3 \%)$ & $6(10.9 \%)$ & $11(20.0 \%)$ \\
\hline Congenital Eye Disease & $3(5.5 \%)$ & $1(1.8 \%)$ & $1(1.8 \%)$ & $5(9.1 \%)$ \\
\hline Infectious of the eye and adnexa & $1(1.8 \%)$ & $3(5.5 \%)$ & $2(3.6 \%)$ & $6(10.9 \%)$ \\
\hline Ocular Trauma & $1(1.8 \%)$ & $3(5.5 \%)$ & $1(1.8 \%)$ & $5(9.1 \%)$ \\
\hline Phthisis bulbs & $0(0.00 \%)$ & $0(0.00 \%)$ & $1(1.8 \%)$ & $1(1.8 \%)$ \\
\hline Refractive error & $1(1.8 \%)$ & $4(7.3 \%)$ & $12(21.8 \%)$ & $17(30.9 \%)$ \\
\hline Disorders of the retina & $0(0.00 \%)$ & $0(0.00 \%)$ & $1(1.8 \%)$ & $1(1.8 \%)$ \\
\hline Vitamin A deficiency & $0(0.00 \%)$ & $1(1.8 \%)$ & $1(1.8 \%)$ & $2(3.6 \%)$ \\
\hline Others & $0(0.00 \%)$ & $2(3.6 \%)$ & $5(9.1 \%)$ & $7(12.7 \%)$ \\
\hline Total & $7(12.7 \%)$ & $1832.7 \%)$ & $30(54.5 \%)$ & $55(100.0 \%)$ \\
\hline
\end{tabular}

\section{DISCUSSION}

In our study refractive errors was most common among 10 - 15 years age group $12(21.8 \%)$ out of total 55 patients. Mehta Sen et al ${ }^{(5)}$ found that refractive error $(38.7 \%)$ was most common ocular morbidity in their study based on central India. Similarly Biswas J et al. ${ }^{(6)}$ studied that refractive error was the most common morbidity (23.7\%). However lower prevalence of refractive error have been reported in other studies ${ }^{(7,8)}$. The most common refractive error observed was Myopia (41.2\%) followed by astigmatism $(35.3 \%)$ and hypermetropia (23.5\%). Refractive error is one of the important reasons for poor school performance.

Disease of the conjunctivitis the second most common morbidity encountered in $20.0 \%$ patients. Chakraborty et al ${ }^{(9)}$ had observed a higher incidence of conjunctivitis $(29.6 \%)$ in this study. Higher prevalence of conjunctivitis has also been observed among school children other studies ${ }^{(6,10)}$.
Infectious of eye disease and adnexa was the third most common ocular morbidity observed in $10.9 \%$ patients followed by the Ocular trauma was $9.1 \%$ patients. The proportions of ocular injuries are higher in developing countries and mainly consist of preventable monocular vision impairment and blindness. Available literature has shown a $5-16 \%$ incidence of cougar trauma in children which was similar to our study results ${ }^{(5,6,11)}$.

\section{CONCLUSION}

From this present study concluded that the refractive errors, conjunctivitis disease resulting from ocular trauma, vitamin A deficiency are common causes of children ocular morbidity under 15 years age group. Most of these diseases are treatable or preventable.

Acknowledgement: None

Conflict of Interest: None 
Mehul Sanghavi. Ocular morbidity among paediatric age group population attending at a tertiary care hospital: a cross sectional study.

\section{Source of Funding: None}

\section{Ethical Approval: Approved}

\section{REFERENCES}

1. World Health Organisation. Preventing blindness in children: report of a WHO/IAPB scientific meeting, Hyderabad, India, 13-17 April 1999.

2. Gilbert C. Changing challenges in the control of blindness in children. Eye (Lond). 2007 Oct; 21 (10): 1338 - 43.

3. Jose R. Present status of the national programme for control of blindness in India. J Community Eye Heal J Indian. 2008; 21: $103-4$.

4. Pratab VB, Lal HB. Pattern of paediatric ocular problem in North India. Indian $\mathbf{J}$ Ophthalmol. 1989371712.

5. Mehta S, Singh M, Chawla A, Agrawal A. Pattern of Ocular Disease in Children Attending Outpatient Department of a Rural Medical College in Central India. Int J Sci Stud 2015; 3 (6): 57 - 60.

6. Biswas J, Saha I, Das D, Bandyopadhyay S, Ray B, Biswas G. Ocular morbidity among children at a tertiary eye care hospital in
Kolkata, West Bengal. Indian $\mathrm{J}$ Public Health 2012; 56: 293 - 6.

7. Nepal BP, Koirala S, Adhikary S, Sharma AK. Ocular Morbidity in School Children in Kathmandu. Br J Ophthalmol 2003; 78: 531 $-4$.

8. Onakpoya $\mathrm{OH}$, Adeoye AO. Childhood eye diseases in south western Nigeria: A tertiary hospital study. Clinics 2009; 64: 47 - 51.

9. Chakraborty C, Mallik S, Chaudhary KP, Das J. Childhood ocular morbidity in eastern India: A tertiary hospital study. Sudan J Public Health 2012; 7: 126 - 30.

10. Khurana AK, Sikka KL, PArmar IP, Agrawal Sk. Ocular morbidity among school children in Rohtak city. Indian J Public Health 1984; 28: 217 - 20.

11. Demissie BS, Demissie ES. Patterns of Eye disease in children visiting tertiary teaching hospital: South western Ethiopia. Ethio J Health Sci 2014; 24: 69 - 74.

How to cite this article: Sanghavi M. Ocular morbidity among paediatric age group population attending at a tertiary care hospital: a cross sectional study. International Journal of Research and Review. 2021; 8(5): 116-119. DOI: https://doi.org/10.52403/ijrr.20210517 